tibilité de différents modes de coordination entre acteurs géographiquement rapprochés. Pour la rendre opérationnelle, il est bien indiqué qu'il importe d'obtenir, de la part des acteurs concernés, la mise en synergie de leurs trajectoires respectives de façon à favoriser l'émergence de l'intérêt commun. Chacun des chapitres comprend des encadrés facilitant la mise en évidence d'exemples concrets. La technopole de Lyon-Guerland et le site de Lacq en Aquitaine servent ici d'illustrations.

Le chapitre sur l'organisation en réseau s'avère particulièrement intéressant pour les lecteurs d'Organisations et territoires. Ses auteurs se demandent dans quelle mesure les réseaux institutionnels jouent le jeu de la proximité géographique. En considérant que cette dernière favorise le processus de développement technologique, ils cherchent à montrer si les réseaux peuvent vraiment favoriser les effets de synergie. Cependant, c'est le dernier chapitre sur les réseaux de transport et de télécommunication qui m'est apparu le plus intéressant. Ces deux types de réseaux non relationnels sont ici envisagés comme des moyens alternatifs et complémentaires de coordination plutôt que sous la forme classique des effets des infrastructures sur le développement économique. Les auteurs remettent en cause les politiques publiques largement fondées sur la logique mécanique de l'effet structurant des infrastructures de transport. Ils semblent être conscients que l'autoroute Félix-Leclerc, reliant Montréal à Québec via Trois-Rivières, n'a eu aucun impact économique sur l'ex-capitale mondiale du papier. Tout comme ils semblent vouloir dire aux Saguenayens que, s'il serait bien qu'une autoroute remplace l'actuelle route 175 , ils ne doivent pas s'illusionner sur les éventuelles retombées économiques susceptibles d'en résulter.

C'est dans ce chapitre que l'on trouve une curieuse définition du capital social puisée dans une thèse récente où le jeune doctorant, de toute évidence, n'a pas subi la même influence que les écrits de Pierre Bourdieu ont eu sur nos sociologues. Qu'on en juge : «Le capital social est constitué de l'ensemble des structures et des équipements du système de santé et d'éducation, des services culturels et de loisirs..." , etc. Exit la cohésion sociale. Pas grave. L'important, c'est que plusieurs trouveront ici et là dans cet ouvrage matière à réflexion.

\section{Jacques de Courson \\ Les élus locaux : qui sont-ils ? Que ont-ils ? Comment travaillent-ils? Paris, Éditions d'organisation, 2001, 215 p.}

Voilà un titre qui ne manquera pas d'accrocher les Québécois à l'heure où les nouvelles Conférences régionales des élus se mettent en branle. Oui, l'acronyme CRÉ va devenir bientôt très familier pour tous ceux qui s'intéressent à la politique locale ou régionale. Leur implantation ne s'est pas faite sans soulever bon nombre d'interrogations, par exemple sur le rôle qui sera désormais dévolu à la société civile. Cependant, il faut en convenir, ce n'est pas depuis l'avènement d'un nouveau gouvernement à la barre du Québec que les élus locaux ont pris du gallon. Le rôle exercé par les maires de petites et moyennes municipalités dans le développement local fait l'objet d'une attention certaine depuis déjà quelques années. Alors, on comprendra la pertinence des questions soulevées dans le titre de cet ouvrage. En effet, qui sontils ces maires et comment remplissent-ils leur mandat eu égard au développement économique ? Ces vingt dernières années, décentralisation oblige, la gestion municipale a dû évoluer. En effet, la mission économique à l'échelon d'un regroupement de villages ou d'une municipalité tend à prendre davantage d'importance.

Dans ces conditions, l'ouvrage de notre collègue Jacques de Courson, de l'Université Paris XII, ne peut passer inaperçu. Mais oui, pour le lecteur québécois, il y a un « mais » : l'ouvrage concerne la réalité hexagonale uniquement. Cependant, ce « mais » n'enlève pas une grande partie de l'intérêt de cet ouvrage. Par exemple, avec le premier chapitre intitulé «Qui sont nos élus locaux? », les Québécois reconnaitront de toute évidence beaucoup de leurs propres élus. Par ailleurs, sur la façon dont ils sont élus (chap. 2), force est d'admettre que l'on se trouve dans un autre monde. Et si ce qui se rapporte au statut rattaché à la fonction d'élu local (chap. 3) colle dans une certaine mesure à tout contexte, on conviendra que le cumul des mandats représente bien une réalité franco-française. En ce qui regarde la vie quotidienne de monsieur le maire (chap.4), encore une fois les exigences de la fonction outre-mer ne sont pas vraiment différentes de 
celles que l'on trouve sur les rives de notre majestueux Saint-Laurent.

Le chapitre 6, «Quel est le mode de gouvernance des élus majeurs ? », m'est apparu comme le plus intéressant même si je n'aime pas l'allusion à des élus qui seraient... mineurs (comme certains arts). Que l'on pense au défi qui attend quotidiennement le maire d'un village de moins de mille habitants où la seule épicerie menace de fermer ses portes; son problème n'a rien de mineur. Les Québécois reconnaîtront certains des leurs parmi les différents profils décrits.

Un livre qui montre bien qu'il importe de parler des élus locaux, car on n'a pas fini d'entendre parler d'eux.

\section{André Joyal}

Université du Québec à Trois-Rivières 